\title{
EL CONTROL DE CONSTITUCIONALIDAD DEL JUEZ ANGLOSAJÓN: ¿POR LA RAZÓN, O POR LA FUERZA? ${ }^{1}$
}

\section{MARIE-LAURE MARTÍNEZ ${ }^{2}$}

RESUMEN: Este trabajo se acerca al problema del ejercicio del control de constitucionalidad de las leyes por medio de su interpretacion. En la primera parte se examinan las bases del control de constitucionalidad de la Corte Suprema de los Estados Unidos, en sus aspectos teóricos y prácticos. En la segunda, se plantea la posibilidad de reconocer el papel de la "fuerza" o de lo menos jurídico, en el control de constitucionalidad estadounidense. En ambas partes del trabajo, se resaltan las similitudes existentes en el control de constitucionalidad en la common law y en los países de tradición decimonónica.

Palabras clave: Control de constitucionalidad - Precedente - Juez anglosajón - Corte Suprema de Estados Unidos

ABSTRACT: This paper approaches the problem of the exercise of the constitutional control of the laws by means of their interpretation. In the first part, the foundations of the constitutional control of the United States Supreme Court are examined, both in theory and in its practical aspects. In the second part, the possibility to recognize the role of the "force" or of the less legal is proposed, in the American constitutionality control. In both parts, actual resemblances are bighlighted in the constitutionality control of the Common Law and in the $19^{\text {th }}$ century tradition countries.

Key words: Constitutionality control - Precedent - Anglo - Saxon judge - United States Supreme Court

SUMARIO: Introducción. I. Las bases del control de constitucionalidad del juez anglosajón (la razón). A. Precedente, stare decisis y los tests (la

\footnotetext{
Este trabajo constituye una versión revisada de aquel que sirviera para aprobar el curso de Derecho Constitucional dirigido por el Dr. Raúl Bertelsen Reperto dentro del Programa "Doctorado en Derecho" impartido por la Pontificia Universidad Católica de Chile, durante el primer semestre de 2004. Arrículo recibido el 6 de diciembre de 2004. Aceprado por el Comité Editorial el 17 de abril de 2005.

2 Abogada. DESS "Jurista International", Universidad Toulouse 1. Magíster en Derecho de la Empresa, P. Universidad Católica de Chile. Doctoranda en Derecho, Pontificia Universidad Católica de Chile. Becaria MECESUP.
} 
teoría). B. Casos: la jurisprudencia sobre la primera enmienda y la doctrina de la Corte Suprema en materia de aborto (la práctica). II. Los factores externos que modelan el control de constitucionalidad del juez anglosajón (la fuerza). A. La búsqueda de un equilibrio entre poderes (una fuerza sociocultural). B. La pertenencia partidista de los jueces constitucionales (una fuerza política). Conclusión.

\section{INTRODUCCIÓN}

En Marbury v. Madison, el emblemático caso de la Corte Suprema de 1803, esta, mediante el juez Marshall, pasó por alto la letra de la ley que examinaba (el Judiciary Act de 1801) para interpretar el artículo III de la Constitución de los Estados Unidos en tal sentido que se arrogue el derecho a ejercer un control de constitucionalidad de las leyes. Esta prerrogativa no está contenida explícitamente en dicho texto. Eso podría interpretarse $-\mathrm{y}$ lo ha sido en gran medida ${ }^{3}$ - como un cambio copernicano en el derecho de esta Nación y una muestra de activismo judicial, especialmente en un país de common law. En efecto, pese a lo cliché de esta observación en cada ejercicio de derecho comparado y a los matices que la formalización por escrito del derecho en la época contemporánea implica, no hay codificación del derecho civil, sino simplemente compilaciones ${ }^{4}$. Además, el precedente tiene una importancia y un reconocimiento sin parangón en un ordenamiento jurídico como el chileno, a pesar de las recientes evoluciones en ese sentido 5 .

Sin embargo, hay que matizar estas observaciones. La Corte Suprema de los Estados Unidos no ha usado este precedente para crear nuevos derechos. Al revés, el Conseil Constitutionnel francés, obrando en la cúspide de un ordenamiento jurídico codificado, supuestamente más rígido en materia de derechos, de lo que se puede y no se puede hacer, ha sido muy creativo. Si bien es cierto que esta última actitud se debe a la falta de declaración de derechos en la Constitución francesa de 1958, ello no lo explica todo. Lo mismo hicieron los tribunales constitucionales alemanes y españoles, cuando las constituciones que les correspondía aplicar sí contenían declaraciones de derecho. Este judicial restraint de la Corte Suprema es para nosotros un primer motivo de extrañeza. Nos lleva a replantearnos todo el control de constitucionalidad en los Estados Unidos

Leer los textos y obras que se "rebelan" ante la inmensa fama alcanzada por el fallo Marbury v. Madison, considerándolo sobrevalorado y malinterpretado.

4 Se trata de los Restatements, o compilaciones de la legislación vigente en cada área del derecho.

5 Zapata larraín, Patricio: "El precedente en la jurisprudencia constitucional chilena y comparada", Revista Chilena de Derecho, vol. 20, 1993, pp. 499-508. 
y a preguntarnos cómo razona el juez constitucional anglosajón en todas las instancias de la judicial review.

Algunas de las preguntas que nos hacemos son las siguientes: antes de la redacción de la Constitución en los Estados Unidos y hoy todavía en Inglaterra, ¿cómo se justifica(ba) el control de constitucionalidad, a falta de una constitución escrita? Si el control de constitucionalidad se inspira en la idea kelseniana de un ordenamiento jurídico piramidal jerárquico, ¿cómo explicar sus existencias en un sistema que, originalmente, como la common law, desconoce este tipo de estructura? Más prosaicamente, dada la importancia del criterio político en la designación de los ministros de la Corte Suprema, ies cierto que se trata solamente de un control (además de difuso) concreto?

La propuesta de investigación anteriormente esbozada no tendría sentido si se tratara solamente de un ejercicio académico aislado de derecho comparado, esto es, si nos limitásemos a una descripción de las particularidades del control de constitucionalidad en los Estados Unidos. El presente trabajo se vincula de dos maneras distintas con el derecho chileno.

En primer lugar, las ideas viajan, en derecho constitucional como en las otras disciplinas. Ya no se trata solamente, como hasta un pasado reciente, de una trasposición de la legislación de los Estados Unidos al ordenamiento jurídico chileno ${ }^{6}$. El efecto difusivo (pervasive) del derecho anglosajón en los ordenamientos jurídicos de los países de tradición decimonónica se manifiesta hasta en las técnicas de interpretación de los jueces. Cómo ya se mencionó ${ }^{7}$, la técnica del precedente, típico de la common law, parece arraigarse en Chile, al menos en el Tribunal Constitucional. Que ello sea el resultado de una verdadera "importación" (consciente o no) por los jueces constitucionales de conceptos o doctrinas elaborados por sus colegas, o que sea el resultado del hecho que, cuando de Constitución se trata, los mismos problemas llevan a las mismas soluciones, de cualquier lado del trópico que uno se encuentre, no cabe en el ámbito del presente estudio. Este se concentra en el ¿cómo?, sin adentrarse en el ¿porqué?

La segunda conexión de este estudio de derecho comparado con el derecho chileno es más simbólica. Como bien es sabido, el lema de esta nación es "por la razón o por la fuerza". Y la verdad es que, al indagar los métodos de razonamiento del juez constitucional anglosajón, nos topamos con la evidencia siguiente: no todo se debe a la razón en las

\footnotetext{
6 Es generalmente el caso de leyes que pretenden adaptar el derecho vigente nacional (que podríamos calificar, con todo respecto por el derecho internacional público, de "no globalizada") a la realidad (esta sí, conforme a la popularizada concepción del mundo moderno como un pueblo global, de "globalizada"), la ley sobre ADRs por ejemplo.

7 ZAPATA, op, cit.
} 
decisiones de la Corte Suprema de los Estados Unidos de Norteamérica. Muchas veces, es la "fuerza", en su acepción política, que explica sus decisiones y fija la pauta del control de constitucionalidad. El parentesco entre lo observado y el lema de la Nación chilena fue para nosotros motivo para ocupar este lema como pauta de redacción y estructuración del presente trabajo.

Por un lado, en la primera parte, examinaremos las bases del control de constitucionalidad de la Corte Suprema de los Estados Unidos, en sus aspectos tanto teóricos (los grandes ítemes de la common law que son la regla del precedente y de la razón decisoria; el modo con el cual los ministros formulan sus estándares tras la formulación de tests de corte pragmático. En suma, todos aquellos elementos que caracterizan el control de constitucionalidad difuso y concreto en su versión estadounidense, como prácticos. Para estudiar aquellos aspectos prácticos, tomaremos como ejemplos las doctrinas elaboradas por la Corte Suprema en torno a la primera enmienda (derecho a la libre expresión y protección del honor, de la honra y de la intimidad) y a la cuarta enmienda (cuyos principios de debido proceso e igualdad fueron las bases para el controvertido e importantísimo caso Roe v. Wade sobre el derecho de las mujeres estadounidenses a abortar).

Por otro lado, la segunda parte, reconoceremos el papel de la "fuerza", de lo no o de lo menos jurídico, en el control de constitucionalidad estadounidense. Son factores externos a la razón. Veremos cómo los nueve jueces se esmeran en preservar el equilibrio de los poderes Ejecutivo y Legislativo y cuidan mucho de no caer en algún tipo de activismo judicial o de gobierno de los jueces, según la expresión consagrada. También trataremos de la designación de los jueces de la Corte Suprema, en la cual el "color" político de los eminentes magistrados, su tendencia republicana o demócrata, cobra singular vigor. Eso lleva al fenómeno de lo que podríamos llamar las "cortes supremas con apellidos": cortes progresistas, intervencionistas, protectoras de los derechos, tales como la Corte WARREN, o al contrario conservadoras y en pro del laissez-faire, como la Corte REHNQUIST.

En ambas partes del trabajo, tendremos a bien resaltar las similitudes existentes en el control de constitucionalidad en la common law y en los países de tradición decimonónica. Por cierto, esta divide y clasifica el control en categorías inexistentes en los Estados Unidos o en Inglaterra, pero existen, como lo mostraremos, indudables paralelos, conexiones, parentescos, que permiten la comparación entre ambos sistemas. Ello es verdad también por las fuentes inspiradoras de las doctrinas elaboradas por el juez constitucional.

Tal como se dio a entender en esta introducción, por "juez anglosajón", nos referimos principalmente al juez de los Estados Unidos, sin excluir referencias ocasionales al derecho inglés. 


\section{LAS BASES DEL CONTROL DE CONSTITUCIONALIDAD DEL JUEZ ANGLOSAJÓN (LA RAZÓN)}

¿Qué puede significar que el juez constitucional anglosajón ejerza racionalmente su control? Los redactores del informe anual de la propia Corte Suprema aportaron en 1993 la siguiente respuesta: "decir que una institución se comporta "racionalmente" es decir que la institución hace elecciones que la hacen avanzar hacia sus metas, desde una perspectiva

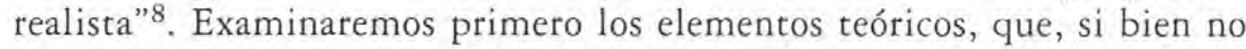
son específicos del control de constitucionalidad, caracterizan todo el proceso judicial de la common law. Se trata de los conocidos principios del precedente y de la razón decisoria, a los cuales agregaremos unas observaciones sobre los tests, o pautas de preguntas que el juez debe hacerse frente a cada caso de la misma especie, para tomar su decisión. Segundo, tomaremos como ejemplos las jurisprudencias elaboradas por la Corte Suprema en torno a la primera y a la cuarta enmiendas.

\section{A. Precedente, stare decisis y los tests (la teoría)}

Al interpretar la Constitución, la Corte Suprema y otras cortes utilizan el método de la common law, decidir caso a caso, elaborando sobre lo que jueces anteriores han decidido. Desde tiempos medievales, jueces en Inglaterra miraron decisiones anteriores y aplicaron estos precedentes a hechos siempre cambiantes. En un caso anterior, digamos, un hombre que dejó suelta una bestia salvaje en el predio de otro fue obligado a pagar daños y perjuicios; ahora si en el próximo caso se trata de un perro peligroso. Aparte del creciente cuerpo de precedentes se derivan normas legales que fueron, y son, la common law. Es la ley hecha por los jueces caso a caso, arraigada en la experiencia. El juez Holmes dijo en su gran libro The Common Law que en las sociedades angloamericanas "la vida del derecho no ha sido lógica: ha sido experiencia"?

Esta definición, que debemos a un ganador del premio Pulitzer que enseñó derecho sin estudiarlo formalmente, es a nuestro juicio la rendición más fiel e ilustrativa de la regla del precedente. Destaca el carácter "sedimentado" del derecho de la common law, cuyas reglas son el producto de la historia, antes de la decisión del legislador, como en los ordenamientos codificados. Pero ahí está precisamente la dificultad:

\footnotetext{
8 N. Eskridge, William, Jr. y P. Frickey, Philip: "The Supreme Court, 1993 term, Foreword: Law as equilibrium", Harvard Law Review vol.108, 1994, pp. 27-108, p. 33. 9 LEWIS, ANTHONY: Make no law, The Sullivan Case and the First Amendment, Vintage Books, 1992 , p. 48. Sin cursivas, salvo para el título del libro mencionado, en el texto original.
} 
históricamente, es el juez el que elabora la norma, no el legislador, no el Congreso.

En cuanto a la stare decisis (razón decisoria), el mismo autor recuerda que su traducción latina es: deja que la decisión valga lo que vale ${ }^{10}$. Es un tema de seguridad jurídica. En base a las decisiones de las cortes, la sociedad en general se hace expectativas. Cambiar una jurisprudencia puede en ese sentido tener un gran efecto destructor, aun si este cambio viene a corregir una decisión anterior errónea. Sin embargo, esta doctrina no rige con tanta estrictez en materia constitucional como en materia contractual. En palabras del juez BRANDEIS, "la Corte se inclina ante las lecciones de la experiencia y la fuerza de un mejor razonamiento"11. Si la Corte Suprema rinde una decisión equivocada, el Congreso no puede corregirla por ley. Esta práctica es más usual en los países de derecho civil. De todos modos, stare decisis y precedente son las dos caras de una misma moneda. Son principios interrelacionados válidos en todos los países regidos por la common law y con tendencia a difundirse fuera de sus fronteras. No tienen el mismo vigor en todos los países: por ejemplo, en Inglaterra, el precedente ha sido siempre más vinculante que en los Estados Unidos. Asimismo, la solución anterior nunca se vuelve a aplicar ad integro, pues se divide entre ratio decidendi (la parte obligatoria de la decisión), y obiter dictum (suertes de "dichos al paso" de menor fuerza vinculante y a veces sirven de índices o de puntos de partida para cambios de decisiones $)^{12}$. Además, al "exportarse", el precedente cambia de sentido. Así, hablando del desarrollo del precedente en el Tribunal Constitucional español, un autor observa: "cuando hablamos de precedente no hablamos de una vinculación al estilo del stare decisis, sino de la eventual aceptación del criterio anteriormente utilizado a la hora de resolver un conflicto de similar o idéntica naturaleza"13. O sea, en el derecho español, el precedente dice relación principalmente con la motivación de las sentencias, y no con las soluciones per se.

¿Cómo se aplican estos principios en materia de judicial review? El artículo III de la Constitución norteamericana no contempla expresamente el poder de la Corte Suprema para chequear la conformidad de las leyes a la Constitución. Este artículo reserva las atribuciones del Poder Judicial a los "casos y controversias", prohibiéndole expresamente al juez otorgar opiniones consultativas (advisory opinions), que podría equiparar a las cuestiones perjudiciales existentes en derecho francés o en el derecho

LEWIS, op. cit. p. 155.

Citado por LEWIS, op. cit. pp. 155-156.

Por una confirmación de este fenómeno en castellano, RIVERo ORTEGA, Ricardo: "Precedente, jurisprudencia y doctrina legal en derecho público: reconsideración de las sentencias como fuente del derecho", Revista de Administración Pública, Madrid, vol. 157, eneroabril de 2002, pp. 89-118, especialmente p. 93. 
comunitario europeo. Además, este artículo establece severos requisitos de legitimación activa para la admisibilidad de las acciones de inconstitucionalidad ${ }^{14}$.

En el estilo elegante y a veces enigmático que es característico de la Constitución norteamericana, los constituyentes (framers) hicieron de la Corte los guardianes del derecho. Fue el controvertido ministro Marshall que, en su opinión en el caso ya citado Marbury v. Madison, estableció que "es enfáticamente de la competencia y el deber del Poder Judicial de decir qué es el derecho. (...) Así, si una ley es en contradicción con la Constitución; si tanto la ley como la Constitución aplica a un caso en particular, de tal manera que la corte deba zanjar el caso en conformidad a la ley, sin preocuparse por la Constitución; o conformemente a la Constitución, sin preocuparse por la ley; la corte debe determinar cual de las reglas en conflicto gobierna el caso. Es de la mismísima esencia del deber judicial (...). Por tanto, la fraseología particular de la Constitución de los Estados Unidos confirma y fortalece el principio, considerado como esencial en todas las constituciones escritas, que una ley contraria a la Constitución es nula; y que las cortes, como las otras administraciones, son vinculadas por este instrumento" 15 .

Esta decisión nunca fue derogada. Por cierto, fue el punto de partida de las múltiples doctrinas y jurisprudencias ${ }^{16}$ que le valen a la Corte Suprema el respeto y el prestigio de los cuales goza en la actualidad. De hecho, no fue primera vez que la Corte Suprema se arrogó el poder de controlar la conformidad de textos de rango inferior a la Constitución, si bien de forma infinitamente más tímida y discreta que en el bullado caso Marbury v. Madison, en donde no se trata nada menos que de gestionar el siempre conflictivo "interregno" entre presidentes. Los dos casos que "anunciaron" la afirmación del poder de control de constitucionalidad fueron las decisiones United States $v$. Yale Todd, de 1794, y Hylton $v$. United States, dos años más tarde.

En el primer caso, el Congreso había dictado una ley que disponía que las cortes de circuito federales debían determinar la validez de las demandas de pensiones de guerra de los antiguos soldados. Aquellas cortes no acogían estas demandas por carecer a su juicio de competencia, ya que la Constitución nada decía al respeto. En el fallo United States v.

14 Para un análisis detallado y en español de las condiciones de admisibilidad de las acciones en inconstitucionalidad, véase Vírgala FORURIA, Eduardo: "Control abstracto y recurso directo de inconstitucionalidad en los Estados Unidos", Revista Española de Derecho Constitucional, año 21, núm. 62, mayo-agosto 2001, pp. 77-124.

15 Fallo Marbury v. Madison, aquí extraído de la Red.

16 Por un estudio profundizado de la diferencia entre las nociones de "doctrina legal", "jurisprudencia" y "tradición jurídica", léase RIVERO ORTEGA, Ricardo, op. cit. p. 92 nota 13, citando a Victoria ItUrralde SeSma, El precedente en el common law, Civitas, Madrid, 1995, y p. 96 , p. 105 y p. 107. 
Todd, la Corte Suprema invalidó la ley en comento, por tratarse de un intento por el Congreso de cargar los tribunales de la Nación con facultades no prescritas por la Constitución. Es dable percibir la ironía de este fallo, al considerarse como anunciador de la judicial review, que aumenta las facultades del Poder Judicial, mientras la Corte Suprema le retira una competencia.

En el segundo caso, se cuestionaba la constitucionalidad de una ley que imponía un impuesto federal en los transportes. La Corte Suprema no declaró expresamente el texto inconstitucional, sino que, al aceptar revisar este caso, se reconoció el poder de examinar la constitucionalidad de las leyes. En este caso, no sancionó la ley, y por tanto, reconoció implícitamente su validez. Este caso merece recordarse, además, por ser uno de los ejemplos más chocantes en donde la Corte Suprema, aun teniendo claro que el Poder Ejecutivo estaban pagando a los abogados de ambas partes, decidió pasar por alto la falta de una real oposición entre las partes $^{17}$.

Desde el punto de vista filosófico, el argumento subyacente a la solución de Marbury v. Madison y de la doctrina de los poderes implícitos desarrollados por el juez Marshall, se inscribe directamente en la línea de Cicerón, Santo Tomás de Aquino, John de Salisbury y Bracton, esto es, juristas para quienes el fondo vale más que la forma, para quienes el contenido de la ley vale más que su fuente y el nivel jerárquico de aquella, a la diferencia de Hobbes, Bentham o Austin ${ }^{18}$.

El tercer elemento que permite entender los razonamientos de la Corte Suprema de los Estados Unidos es la práctica de los tests, esto es, los estándares o pautas, formuladas como listas de preguntas que deben contestar los jueces antes de tomar su decisión. Un ejemplo de ellos es el test de la malicia real en el caso New York Times v. Sullivan de 1964, en materia de libre expresión (primera enmienda). Este reemplazó al test del "peligro claro y presente" (clear and present danger test) desarrollado por los jueces Holmes y Brandeis, que prevalecía anteriormente. Los ejemplos son innumerables: cada disciplina del derecho dio lugar a una seguidilla de tests cuyas alteraciones y cambios informan las jurisprudencias de la Corte Suprema en las diferentes materias de su competencia.

El precedente, la razón decisoria, y la técnica de los tests están complementados por ciertas actitudes fácticas de la Corte, actitudes que sobreviven a los años y a los cambios de "cortes": la autolimitación del juez constitucional (self restraint) o respeto por el juez de la separación de los poderes, la conciencia de los jueces de que sus decisiones son una fuente de derecho y que las jurisprudencias que elabora constituye una pauta

VíRgala ForURIA, Eduardo: op. cit. p. 86.

Dean, Howard E.: Judicial Review and Democracy, Random House, Nueva York, 1966, pp. 28-33, especialmente p. 29. 
respetada y seguida por los demás agentes jurídicos. La self restraint del juez fue justificada del modo siguiente: es conveniente y adecuado para los jueces mantenerse en una posición no conflictiva, dado el ya arduo nivel de agresividad característico de la vida institucional en los Estados Unidos. Por tanto, tienden a concebir el derecho como un juego de equilibrio entre las tres ramas de poderes, y que, así concebido, el derecho tiene una mejor "calidad" que si fuese producido por una sola institución ${ }^{19}$.

B. Casos: la jurisprudencia sobre la primera enmienda y la doctrina de la Corte Suprema en materia de aborto (la práctica)

No cabe en el modesto ámbito de este trabajo establecer una tipología de las doctrinas legales creadas por la Corte Suprema respecto a todas las disposiciones de la Constitución, para deducir del catálogo resultante un cuadro de la práctica de la Corte Suprema en materia de control de constitucionalidad. Tomaremos solamente como ejemplos la jurisprudencia en torno a la primera enmienda y la jurisprudencia en materia de aborto.

La primera enmienda de la Constitución dio pie a una amplísima jurisprudencia de la Corte Suprema. El problema principal que plantean las leyes que infringen o están sospechadas de infringir la libertad de expresión es su amplitud. En vez de suprimir in toto la libertad de expresión, la limitan demasiado. Son excesivas. Frente a este tipo de casos, la actitud de la Corte Suprema ha sido triple. Acorde a la primera actitud que adoptó, lo que los jueces aprecian es el resultado concreto de la aplicación de la norma al momento en que se le somete la ley ${ }^{20}$. Si el demandante no logra demostrar que no sufrió perjuicio alguno o suficiente, la ley que ataca no puede ser invalidada, sin perjuicio de que en realidad, puede ser dañina o disconforme a la Constitución.

Acorde a la segunda actitud adoptada por la Corte Suprema, se declara de plano inválida la totalidad de una ley, toda vez que los beneficios que traerá a intereses gubernamentales reconocidos como válidos, pesan menos en la balanza que los daños que provoca a los intereses de la comunidad en materia de expresión. Sin embargo, al igual que el primer método, no es precisamente un método que la Corte Suprema desarrolló sola y específicamente en materia de libre expresión. Por ello, la Corte fue recurriendo a un tercer método: la overbreadth doctrine, tras la cual, en vez de anular una por una las aplicaciones nefastas de una ley

ESKRIDGE et al: : p. 35.

AA.VV:: "The First Amendment Overbreadth Doctrine", Harvard Law Review, vol. 83, núm. 4, febrero de 1970, pp. 844-927, p. 848. 
cuyo ámbito es tan amplio que vulnera la libertad de expresión, la Corte anula el texto cuestionado y lo reenvía al Congreso con vistas a que se le corrija y redacte nuevamente. El control resultante es mucho más abstracto y contradice la visión clásica del control de constitucionalidad anglosajón como un control difuso y sobre todo, concreto.

Si estos tres, o para simplificar, dos, métodos (ya que el segundo está a veces absorto en el primero), se ponen en perspectiva, vemos que el primero (más conocido como as applied method) es menos, en rigor, que un control absolutamente concreto. Tampoco puede resumirse a un principio sobre las condiciones con que debe cumplir una acción de judicial review y en particular, con el interés que debe demostrar el demandante. Se trata más bien, de una "teoría sobre los límites de una manera de rendir decisiones de justicia que sean confiables y eficaces" 21 . Se engarza con la política de autolimitación y restraint ya mencionada, en la medida en que se trata de un consejo prudencial, más que "una práctica intrínseca de la teoría de control de constitucionalidad de las leyes: amplias cuestiones acerca de la validez de las leyes deberían ser postergadas y se deberían evitar al máximo anulaciones automáticas, de modo que sea minimizado el peligro de fricciones institucionales" 22 . Otras ideas relacionadas con la aplicación de este método incluyen la falta de medios de la Corte Suprema para lanzarse en un control más abstracto.

Contrastando con el primer método, la overbreadth doctrine se aleja del catálogo de "virtudes pasivas" 23 que hizo suya la Corte Suprema por muchos años. Proyecta también la imagen de una Corte más activa, que le saca todo el partido posible a la facultad de revisión y control constitucional que se concedió con timidez siglo y medio antes. Al moverse hacia un control más abstracto, más "europeo", sin esperar o exigir que el demandante aporte la prueba del daño real e inevitable que lo afectó por culpa de la ley atacada, el juez constitucional anglosajón se muestra más preocupado por prevenir violaciones de la libertad de expresión, no tanto por castigarlas. La Corte Suprema se muestra también más flexible a la hora de apreciar la madurez (ripeness) de la acción. Admite que el ciudadano americano se queje de una ley porque es probable que se produzca un daño que le perjudicará.

Si hay un área del derecho en donde el papel de la Corte Suprema es fundamental, se trata de la interrupción del embarazo. Deriva de la deducción por la Corte Suprema de un derecho a la intimidad, a partir de las primera, tercera, cuarta y novena enmiendas, en el fallo Union

AA.VV.: "The First Amendment Overbreadth Doctrine", op. cit. p.849.

AA.VV.: "The First Amendment Overbreadth Doctrine", id.

Según la expresión del afamado profesor Bickel, en Bickel: "The Supreme Courr, 1960 term, Foreword: The Passive Virtues", Harvard Law Review vol.75, 1961, p. 40. 
Pacific R. Co. v. Botsford de 1891. Esta decisión fue progresiva ${ }^{24}$. En primer lugar, en Griswold v. State of Connecticut, de 1965, confirmado por Eisenstadt v. Baird, en 1972, el juez Douglas, quien redactó la opinión mayoritaria, se preguntó si “ ¿estamos listos para autorizar la policía a penetrar en el recinto sagrado de la cámara conyugal en busca de prueba de uso de contraceptivos?". Al contestar por la negativa, invalidó una ley estatal que prohibía el recurso de las parejas casadas a los contraceptivos. Esta "evolución" culminó con el fallo Roe v. Wade de 22 de enero de 1973. El ministro Blackmun estableció lo siguiente: "Este derecho a la intimidad, sea o no fundado en las nociones de libertad individual y de límite a la acción del Estado contenidas en la decimocuarta enmienda, como lo pensamos, o, como lo ha decidido la Corte de distrito, sobre la reserva de derechos de la novena enmienda es suficientemente amplia para entender la decisión de una mujer de poner fin a un embarazo" 25 . Enfrentado a la posibilidad de encontrar el asidero de este derecho "innominado" en la regla del debido proceso o en la regla de igualdad de derechos, como lo reclamaban las feministas, la Corte Suprema eligió la primera.

Este derecho una vez "descubierto" por el juez constitucional se encuentra inmediatamente relativizado al ser comparado con el interés del Estado, que abarca, ya sea, la salud de la madre, ya sea, la protección de la potencialidad de vida que materializa el feto. Usando sus facultades al máximo tras un control estricto (strict scrutiny) por tratarse de un derecho calificado como fundamental de la mujer, la Corte Suprema forjó la llamada regla de los tres trimestres. Esta regla impide al Estado prohibir el aborto durante el primer trimestre posterior a la fecha de concepción y hasta el fin del primer trimestre. Durante este segundo trimestre, el tipo de legislación que la Corte Suprema autorizó -ejemplos mediante-, abarcó la exigencia de condiciones para permitir el aborto o de ciertos equipos medicales para que se lleven a cabo estos procesos. En fin, a partir del tercer trimestre, los Estados están autorizados a adoptar normas abiertamente favorables a la protección del feto, para que se le permita sobrevivir fuera del cuerpo de su madre. En ningún momento se pronunciaron los nueve jueces acerca de lo que consideraban ser el inicio de la vida o los derechos del feto en cuanto persona. Eso sí, fijaron la viabilidad del feto a veinticuatro o veintiocho semanas ${ }^{26}$.

Esta decisión relanzó la controversia entre las escuelas "interpretativistas" y "no interpretativistas" de la Constitución. Los primeros piensan que la Corte Suprema debe interpretar la Carta Fundamental en función

\footnotetext{
24 Por un recuento de esta jurisprudencia, desde la perspectiva, en alguna medida pro abortista a nuestro parecer, léase Custos, Dominique: "La Cour Suprême américaine er la liberté d'avortement", Revue du Droit Public, núm. 5, 1995, pp. 1119-1155.

Custos, Dominique: op. cit. p. 1124, nota 18.
} 
de los principios de libertad y de igualdad, los cuales resumen en última instancia el ideal americano. Es válida toda interpretación que, teleológicamente, satisface estos dos objetivos, sin importar que los derechos que vayan surgiendo en el transcurso de esta interpretación sean o no contenidos expresamente en la letra de la Constitución. La segunda corriente, de corte conservador, milita en favor de una interpretación literal del texto, en función del "original intent" de los constituyentes históricos. De transformarse en política oficial de la Corte, ello significaría evidentemente un retroceso en materia de derechos de las personas, especialmente para todos aquellos derechos creados o deducidos por la Corte Suprema, pese a que, como lo señalamos en la introducción, esta institución se mostró siempre cuidadosa y poco "creativa", en ese ámbito.

En los años siguientes, la jurisprudencia en materia de aborto fue fluctuante, aunque manteniéndose globalmente en la línea del fallo Roe $v$. Wade, hasta que en la decisión Webster v. Reproductive Health Services de 1989, la Corte no consideró como disconforme a la Constitución una ley del Estado de Missouri cuyo preámbulo postulaba claramente una teoría del inicio de la vida pro life (hostil al derecho al aborto) y cuyo articulado prohibía el uso de equipos, fondos y personal público para la realización de abortos no terapéuticos. La decisión hacía amplia referencia a fallos posteriores a Roe $v$. Wade, reinterpretándolos desde una nueva perspectiva. Se declara así que el mecanismo de los tres trimestres es demasiado preciso como para ser conforme a la redacción literaria de la Constitución y que permitir al Estado declararse en favor de la "potencialidad de la vida" solamente después de la fecha estimada de viabilidad es irrealista. De lo cual se ve claramente que el mecanismo de los tres trimestres se ve invalidado. ¿Dada la existencia del principio de stare decisis, cómo se justifica este cambio de solución? La Corte responde anticipadamente a la pregunta al indicar que son susceptibles de ser abandonados todos aquellos razonamientos "viciados en su principio e inexplotables en la práctica". El empleado en Roe $v$. Wade hace parte de aquellos.

Este nuevo método de razonamiento fue profundizado en Planned Parenthood of Southern Pennsylvania v. Casey de 29 de junio de 1992. En esta decisión, que la llevó a plantearse el problema de la validez del consentimiento del marido al aborto, la Corte estimó que "solo es en la medida en que constituye un obstáculo excesivo que el hecho por el Estado de favorecer la continuación del embarazo o la protección de la salud debe ser calificado de violación de la Constitución"27. 
Más allá de las explicaciones y teorías que se pueden elaborar al respecto, parece evidente que factores ajenos a la sola razón influyeron en este cambio de jurisprudencia, especialmente la composición de los jueces, y la pertenencia política de aquellas, más republicana en 1992 que en 1973, cuando los republicanos son considerados más proclives a rechazar el aborto. A la larga, ¿que será de la jurisprudencia norteamericana sobre el aborto? Si las soluciones Webster y Casey se prolongan en el tiempo, y la interpretación que hace la Corte del test que se autoimpuso de "obstáculo excesivo" les hace imposible a las mujeres recurrir al aborto (sin perjuicio de todos los reparos morales que suscita este tipo de práctica), entonces habrá de concluir que sí ha habido cambio de jurisprudencia y que cedió el stare decisis frente a las nuevas fuerzas en presencia en el seno de la Corte. Dice un autor que tenemos "por un lado los jueces O'Connor, Kennedy, Souter y Stevens (que conforman la mayoría con el juez Blackmun) acampan en una concepción exigente del stare decisis que les prohíbe echar por tierra los elementos de la herencia de las Cortes Warren y Burger aun cuando lo desearían personalmente. Por otro, el Presidente de la Corte Rehnquist y los jueces White, Scalia y Thomas" 28 . Es el papel y la potencia de estas fuerzas en el control de constitucionalidad del juez anglosajón que evaluaremos a continuación.

\section{LOS FACTORES EXTERNOS QUE MODELAN EL CONTROL DE CONS- TITUCIONALIDAD DEL JUEZ ANGLOSAJÓN (LA FUERZA)}

En Marbury v. Madison, el vocabulario empleado por el juez Marshall fue considerado como enérgico e ilustra por muchos años el activismo judicial, pese a que, a juicio nuestro, la decisión del juez histórico es más salomónica que agresiva. Lo único que preveía explícitamente la Constitución era el poder de la Corte Suprema de velar por el equilibrio de competencias entre los Estados y la federación, para que las fuerzas centrípetas todavía activas en los inicios de la Nación no fuesen a ganar y disgregar la joven federación. Tal como se constató en la primera parte, poca base existía para permitir que la Corte Suprema fuese a controlar, ya no los actos de las legislaciones estatales, sino los actos del legislador federal. Al otorgarse esta misión, la Corte iniciaba una labor de "equilibrista", un largo trabajo de búsqueda de un compromiso entre el Congreso y el Ejecutivo, por una parte, y entre el Congreso y el Poder Judicial, por otra. En este quehacer prudencial, marcado por la moderación y una concepción restric- 
tiva de sus funciones, la Corte no logra escapar completamente a los estigmas políticos que presiden a la designación de cada uno de los magistrados.

\section{A. La búsqueda de un equilibrio entre poderes (una fuerza socio- cultural)}

El tema de la self restraint o self retreat es una constante de la jurisprudencia de la Corte Suprema. Todo pasa como si, después de haber sacudido el tablero institucional, siglo y medio atrás, la Corte se contuvo en un papel de discreto observador y árbitro de los debates más álgidos. Sin embargo, en ocasiones, adoptó un papel más protagónico.

¿Cuál es el origen de la self restraint? Si bien resumió la actitud de la Corte desde sus inicios, su formulación llegó al final del siglo diecinueve, con un escrito del profesor James Bradley Thayer titulado "The Origin and Scope of the American Doctrine of Constitutional Law"29 (el origen y el ámbito de la doctrina americana del derecho constitucional). Reconociendo el carácter antirrepublicano del control de constitucionalidad, el profesor afirmó que conduce el juez a desempeñar el papel del legislador, a ejercer el temido "gobierno de los jueces" y a inmiscuirse en la "administración política del gobierno"30. A la postre, una concepción agresiva del control de constitucionalidad sería contraria a la democracia, La democracia implica que el pueblo elija sus representantes para gobernarlo. El control de constitucionalidad equivale de cierta forma a gobernar. Sin embargo, los jueces de la Corte Suprema no son elegidos por el pueblo. Por tanto, el control de constitucionalidad no sería democrático y no tendría lugar alguno en el sistema jurídico norteamericano. Las amargas críticas hechas al juez Marshall y a su opinión en Marbury v. Madison, el calificativo de "golpe de Estado" que se le puso a este fallo, serían justificados.

Tales peligros exigen que el juez tenga una conciencia especial de la gravedad de su trabajo. En palabras de Thayer, "una Ley del legislador no debe ser declarada nula a menos que la violación de la Constitución sea tan manifiesta que no deja lugar para dudar razonablemente de ello" 31 . El hecho que una ley sea razonable, explicable, le confiere un carácter constitucional.

Esta severidad del profesor Thayer puede explicarse al mirar el contexto judicial del momento: la Corte Suprema de aquellos años se mos-

DEAN, Howard E.: op. cit. p. 112-118

DEAN, Howard E.: p. 113.

DEAN, Howard E.: id. Las mayúsculas o su carencia están en el original. Nuestra traducción. 
traba activamente partidaria de la política económica del laissez-faire. Al eminente profesor le pareció pertinente recordarles a los jueces su deber de humildad y que, al tomar sus decisiones, el sentido de lo razonable, de lo permisible y de lo adecuado según la tradición ancestral de la common law debían prevalecer. De hecho, se le ha reprochado a Thayer acercar en demasía el control de constitucionalidad al análisis en materia de torts o de derecho penal ${ }^{32}$.

La doctrina de la self restraint prosperó, encontrando en cada generación de juristas enérgicos defensores, ya sea abogados o miembros de la Corte. Así, el juez Brandeis, que era por lo demás un juez a menudo disidente, con ideas novedosas y una peculiar visión del derecho, junto con su colega Holmes, justificó la voluntad de la Corte de autolimitarse para preservar el statu quo entre los poderes institucionales existentes con el aforismo siguiente: "La cosa más importante que hacemos es que no hacemos"33. Otro prestigioso exponente de la doctrina de la autolimitación fue el Presidente de la Corte Stone. En United States v. Butler, explicó que "(...) mientras que el ejercicio inconstitucional del poder por las ramas ejecutivas y legislativas son sujetas al control de constitucionalidad, el único control de nuestro propio ejercicio del poder es nuestro sentido personal de la autolimitación. Porque la remoción de leyes irrazonables de las recopilaciones es una incitación a la mentira, no a las cortes, sino a los votos y a los procesos del gobierno democrático"34.

Los jueces Frankfurter y Hand, los juristas Bernard Schwartz y Paul A. Freund han sido también defensores de la autolimitación judicial y la conceptualización en sus respectivos fallos y obras. Otros elaboraron una doctrina que pretende matizar la autolimitación y optimizar sus efectos. Se conoce como la doctrina de las libertades preferidas (preferred freedoms doctrine). Por algunos, las libertades y derechos fundados en la primera enmienda de la Constitución de los Estados Unidos serían los más importantes, algo así como el alfa y omega de todas las demás libertades y derechos de los ciudadanos norteamericanos o, en palabras del juez Cardozo "la matriz, la condición indispensable de casi todos los otros tipos de libertades" 35 .

El grado de escrutinio de los jueces a la hora de examinar leyes susceptibles de vulnerar la libre expresión debería ser alto. No cabría, para aquellas violaciones, un control de constitucionalidad superficial o limitado a lo que en derecho administrativo francés se llaman los errores manifiestos. La autolimitación de los jueces y su respeto por el equilibrio

DEAN, Howard E.: id.

DEAN, Howard E.: op. cit. p. 119. Fallo Ashwander v. TVA, de 1936.

DEAN, Howard E.: op. cit. p. 120.

DEAN, Howard E.: op. cit. p. 129, citando la opinión del juez Cardozo en el fallo Palko v. Connecticut de 1937. 
de los poderes institucionales tal cual resultó de las elecciones del pueblo encontraría su límite en las libertades de la primera enmienda, de la misma manera que el control de constitucionalidad, cuya creación en Marbury v. Madison fue finalmente respetada por el Ejecutivo y el Legislativo, encuentra su límite en dicha autolimitación.

Globalmente, sobre la Corte Suprema y el respeto de la separación de los poderes, estamos de acuerdo con que "las decisiones de la Corte en esta materia reflejan, en efecto, un ir y venir permanente entre un enfoque pragmático y flexible, haciendo hincapié en los frenos y contrapesos y el solapamiento entre los diferentes poderes, y otro enfoque más rígido y formalista que favorece una noción doctrinal de la separación de poderes" 36 .

\section{B. La pertenencia partidista de los jueces constitucionales (una fuerza política)}

La autolimitación que estudia el acápite anterior es a veces calificada de deferencia de los jueces hacia quienes los nombraron. Tocamos aquí en un punto de índole más sociocultural que jurídico. Históricamente, a todos los jueces de la Corte Suprema se les conoce por su tendencia política y, a la diferencia de lo que ocurre en Francia con los miembros del Conseil Constitutionnel, ello se refleja de modo sistemático en sus decisiones, por lo cual aquellas revisten en ocasiones un carácter predecible. No parece haber, dentro de los jueces de la Corte Suprema según la expresión recién consagrada en Francia, deber de ingratitud alguno, aunque es dable señalar una tendencia quizás más irreverente del lado de aquellos jueces de tendencia demócrata ${ }^{37}$. Por ejemplo, el juez Clarence Thomas, nombrado con dificultades por el Presidente Reagan en la década de los ochenta, ha mantenido firme y clara su tendencia conservadora republicana en cada una de las opiniones que ha redactado o participado. Este fenómeno culminó en las ya mencionadas "cortes con apellidos", debido a la influencia preponderante de su Presidente. Así, se han hablado de las Cortes Warren y Burger, como cortes "demócratas".

Parece posible esbozar aquí un somero panorama de las fases políticas por las cuales ha pasado la Corte desde sus inicios. El juez Marshall fue nombrado por el presidente federalista Adams y la Corte Suprema practicó un control de constitucionalidad renovado (no solamente limitado a la verificación de conformidad de los actos de los Estados a la

\footnotetext{
36 Fisher, Louis, y MourtadA-SABbah, Nada: "La Cour Suprême des États-Unis: interprète souverain de la Constitution?", Revue du Droit Public, núm, 4, 2002, pp. 1205-1245, p. 1235 .

37. Léase supra nuestros comentarios en la jurisprudencia del aborto después de la decisión Webster.
} 
Constitución en cuanto Carta Fundamental de la recién nacida federación) con bastantes tensiones hasta mediados del siglo diecinueve. Los relatos de la hostilidad abierta entre el Presidente Jefferson y el juez Marshall conforman un capítulo clásico de los cursos de derecho constitucional americano.

A fines de siglo diecinueve e inicios del siglo veinte, la Corte Suprema actuó con dinamismo y hasta agresividad, rindiendo decisiones abiertamente "republicanas" y "nordistas", pues favorecían los intereses del capitalismo puro y duro, sin trabas, de los industriales del noreste del país. El caso simbólico de aquella época es el fallo Lochner v. New York de 1905, que muestra una Corte que pone por sobre la razón jurídica la creencia (política) de que el laissez faire económico era lo mejor para los Estados Unidos. Otra constante de esta época fue cierta actitud hostil a los comunistas (red scare, el temor rojo) que pudo percibirse por ejemplo en el caso Gitlow. Es costumbre constatar las disidencias de los dos mismos jueces, Holmes y Brandeis, de personalidades más liberales aunque extremadamente diferentes, en los fallos de esta época ${ }^{38}$.

La actitud republicana partidaria del no intervencionismo económico se prolongará, con algunos años de calma, hasta el gobierno del Presidente Roosevelt, cuyo programa de intervencionismo económico (con marcados ribetes keynesianos) no fue del agrado de la Corte, que invalidó cuanto pudo de las leyes en ese sentido, a tal punto que el Presidente presentó ante el Congreso un proyecto de modificación de la Constitución, enfocado a la transformación de la Corte Suprema. Este proyecto no corrió buena suerte. La Corte siguió siendo una institución "republicana" hasta finales de los años cincuenta. Luego las nominaciones sucesivas de los distintos presidentes la hicieron pasar del lado demócrata, hasta inicios de los noventa. Sin embargo, la Corte Suprema se mantuvo muy moderada y sigilosa de no perturbar el equilibrio político, especialmente a partir de mitades de los años setenta. A inicios de los años noventa, merced a las nominaciones de los señores Reagan y luego Bush, la Corte se "republicanizó" y es la Corte que tenemos en la actualidad.

\section{CONCLUSIÓN}

Para los constituyentes históricos, cuyas ideas fueron difundidas antes y después de la redacción de la Constitución de los Estados Unidos mediante el jurista Hamilton, la Corte Suprema era un órgano "sin es-

38 Por una descripción en materia de libre expresión de las opiniones de aquellos dos ministros de la Corte Suprema, léase LEWIS, op. cit., capítulo 9, "Holmes and Brandeis, dissenting", pp. 80-89. 
pada y sin billetera"39. En 1803, con Marbury v.Madison, la Corte, por así decirlo, se "armó". Pasó de guardiana del federalismo a vigilante de las luchas entre el legislador y el Presidente y luego, a protectora de los derechos de las personas.

Esperamos haber mostrado en este trabajo sus herramientas para tomar decisiones: el precedente y la razón decisoria, por un lado. Para construir soluciones, formula preguntas básicas, muchas veces en varias etapas: los tests. Estos tests sirven a los estudiosos del derecho a predecir las soluciones futuras y son una forma para la Corte de cumplir con su papel de superior de las cortes supremas estatales, unificando y enseñando a los jueces cómo tomar sus decisiones. A estas reglas se agregan la práctica de virtudes comunes a la common law como la búsqueda de compromisos, el recurso a la razonabilidad, a lo habitual.

Pero la Corte Suprema de los Estados Unidos no es impermeable. Factores externos, como cierta voluntad de supervivencia, de preservación de sus propios intereses y de su prestigio la retienen de inmiscuirse en la batalla entre legislador y Ejecutivo, la cual, dado el régimen de estricta separación de los poderes vigentes en los Estados Unidos, se torna muchas veces muy violenta. Otro factor importante es la tendencia política de los jueces, que se mantienen por lo general fieles a la obediencia política que los designó. Estos factores externos no obstan a que la labor de la Corte haya sido destacable y que los tests y nociones que usa para tomar sus decisiones terminan muchas veces por cruzar las fronteras.

Habrá de esperar que el espíritu de cuerpo, la conciencia de su propio prestigio y el valor personal de cada uno de sus miembros, a falta de fundamentos más claros en la Constitución, le permitan mantener en alto este modelo de control de constitucionalidad. Pues bien, a la diferencia de los sistemas alemán y francés, las características de este control, la intensidad del control a aplicar a cada caso, la posibilidad o no de alejarse de la letra de la Constitución para extrapolar y deducir de su espíritu derechos adaptados a las necesidades de la modernidad, fueron exclusivamente el resultado del esfuerzo de la Corte. Las condiciones de admisibilidad de las causas no son muy diferentes de aquellas exigidas por un asunto común.

Además, en la actualidad, asistimos a un auge de textos ${ }^{40}$ que avanzan la idea de que el alcance del fallo Marbury v. Madison fue malentendido y que no implicaría en verdad ninguna idea de supremacía de la Corte sobre el resto del ordenamiento. Tampoco impediría, como es el

\footnotetext{
39 Citado por virtualmente todos lo profesores o estudiosos del derecho constitucional anglosajón. Véase por ejemplo, LEWIS, op. cit. p. 89.

to VAN AlSTYNe, William: "A Critical Guide to Marbury v. Madison", Duke Law Journal, 1969 , p. 11. Se publicó recientemente un libro aún más crítico, Robert LOWRY CIINTON: Exploring Constitutional Conflicts, Marbury v. Madison and Judicial Review.
} 
caso en la práctica actual, que las interpretaciones constitucionales del Presidente o del Congreso prevalezcan por sobre las de la Corte. ¿Qué influencia tendrán la difusión de estas ideas sobre el control de constitucionalidad de los Estados Unidos? Solo el futuro lo dirá.

\section{BIBLIOGRAFÍA CITADA}

- AA. VV.: "The First Amendment Overbreadth Doctrine", Harvard Law Review, vol. 83, núm. 4, febrero de 1970.

- BICKEL: "The Supreme Court, 1960 term, Foreword: The Passive Virtues", Harvard Law Review vol.75, 1961.

- Custos, Dominique: "La Cour Suprême américaine et la liberté d'avortement", Revue du Droit Public, núm. 5, 1995.

- Dean, Howard E.: Judicial Review and Democracy, Random House, Nueva York, 1966.

- Eskridge N., William, Jr. y FrICKey P., Philip: "The Supreme Court, 1993 term, Foreword: Law as equilibrium", Harvard Law Review vol.108, 1994.

- Fisher, Louis, y Mourtada-Sabbah, Nada: "La Cour Suprême des États-Unis: interprète souverain de la Constitution?", Revue du Droit Public, núm. 4, 2002.

- LEWIS, Anthony: Make no Law, The Sullivan Case and the First Amendment, Vintage Books, 1992.

- Lowry Clinton, Robert: Exploring Constitutional Conflicts, Marbury v. Madison and Judicial Review.

- Rivero Ortega, Ricardo: "Precedente, jurisprudencia y doctrina legal en derecho público: reconsideración de las sentencias como fuente del derecho", Revista de Administración Pública, Madrid, vol. 157, enero-abril de 2002.

- Vírgala Foruria, Eduardo: "Control abstracto y recurso directo de inconstitucionalidad en los Estados Unidos", Revista Española de Derecho Constitucional, año 21, núm. 62, mayo-agosto 2001.

- VAn Alstyne, William: "A Critical Guide to Marbury v. Madison", Duke Law Journal, 1969.

- Zapata larraín, Patricio: "El precedente en la jurisprudencia constitucional chilena y comparada", Revista Chilena de Derecho, vol. $20,1993$. 